\title{
Pyrimidine biosynthetic pathway of Pseudomonas fluorescens
}

\author{
Chien-Peng Chu† and Thomas P. West* + \\ Department of Biological Sciences, Institute of Genetics, University of Southern Mississippi, Hattiesburg, \\ Mississippi 39406, USA
}

(Received 23 October 1989; revised 3 January 1990; accepted 23 January 1990)

\begin{abstract}
Pyrimidine biosynthesis in Pseudomonas fluorescens strain A126 was investigated. In this study, de novo pyrimidine biosynthetic pathway mutant strains were isolated using both conventional mutagenesis and transposon mutagenesis. The resulting mutant strains were deficient for either aspartate transcarbamoylase, dihydroorotase or orotate phosphoribosyltransferase activity. Uracil, uridine or cytosine could support the growth of every mutant strain selected. In addition, the aspartate transcarbamoylase mutant strains could utilize orotic acid to sustain their growth while the orotidine-5'-monophosphate decarboxylase mutant strains grew slowly upon uridine 5'monophosphate. The wild-type strain and the mutant strains were used to study possible regulation of de novo pyrimidine biosynthesis in $\boldsymbol{P}$. fluorescens. Dihydroorotase specific activity more than doubled after the wild-type cells were grown in orotic acid relative to unsupplemented minimal-medium-grown cells. Starving the mutant strains of pyrimidines also influenced the levels of several de novo pyrimidine biosynthetic pathway enzyme activities.
\end{abstract}

\section{Introduction}

The de novo pyrimidine biosynthetic pathway, which culminates with the formation of uridine 5 '-monophosphate (UMP), has five enzymic steps unique to pyrimidine synthesis (O'Donovan \& Neuhard, 1970). The enzymes involved in this pathway are aspartate transcarbamoylase, dihydroorotase, dihydroorotate dehydrogenase, orotate phosphoribosyltransferase and orotidine-5'monophosphate (OMP) decarboxylase. Few studies have examined de novo pyrimidine biosynthesis in species of Pseudomonas. Two previous studies have investigated the regulation of the enzymes of de novo pyrimidine biosynthesis in Pseudomonas aeruginosa and Pseudomonas putida (Isaac \& Holloway, 1968; Condon et al., 1976). There was no apparent regulation in either microorganism. In contrast, several studies have shown that aspartate transcarbamoylase in various Pseudomonas species is regulated at the level of enzyme activity by pyrimidine and purine nucleotides, which led many of the authors to conclude that this may be how de novo pyrimidine biosynthesis is controlled (Neumann \&

$\dagger$ Present address: Department of Microbiology and Immunology, Temple University, Philadelphia, Pennsylvania 19140, USA.

$\ddagger$ Present address: Station Biochemistry, South Dakota State University, Brookings, South Dakota 57007, USA.

Abbreviation: OMP, orotidine 5'-monophosphate.
Jones, 1964; Isaac \& Holloway, 1968; Adair \& Jones, 1972; Condon et al., 1976).

In this study, de novo pyrimidine biosynthesis was explored in Pseudomonas fluorescens. This entailed the isolation of several pyrimidine-requiring mutant strains. Each strain was subsequently characterized as to its auxotrophy as well as to its enzymic defect. Possible regulation of de novo pyrimidine biosynthetic pathway enzyme synthesis was also examined.

\section{Methods}

Growth media. A glucose minimal medium (Stanier, 1947) was utilized as previously modified (West, 1989). For solid medium, $2 \%$ $(w / v)$ agar was added.

Isolation of mutant strains. P. fluorescens strain A126 served as the wild-type strain in this study (Stanier et al., 1966). To isolate strains exhibiting uracil auxotrophy in $\boldsymbol{P}$. fuorescens, two different methods were selected. The initial methodology involved transposon mutagenesis using the transfer of a 'suicide' plasmid. The plasmid pJB4JI, which contains Tn5, was transferred from Escherichia coli 1830 to $P$. fluorescens by bacterial conjugation (Beringer et al., 1978; Gantotti et al., 1981; Monticello et al., 1985). Kanamycin resistance is encoded by Tn5 located on the plasmid. Transfer was accomplished by mixing exponential phase cultures of $E$. coli and $P$. fluorescens (5:1 ratio). After the cells were collected on $0.45 \mu \mathrm{m}$ membrane filters $(25 \mathrm{~mm})$, the filters were placed on minimal medium agar plates containing $50 \mathrm{mg}$ kanamycin and uracil $1^{-1}$. After $24-48 \mathrm{~h}$ at $30^{\circ} \mathrm{C}$, the cells were washed from the filters using $0.85 \% \mathrm{NaCl}$. Dilutions of the resulting suspensions were made and then used to inoculate minimal medium 
containing novobiocin, uracil and kanamycin (all $50 \mathrm{mg} \mathrm{1}^{-1}$ ) (Monticello et al., 1985). The bacteria were grown overnight in this medium at $30^{\circ} \mathrm{C}$. Each culture of the mutagenized cells was diluted and spread onto minimal medium agar plates containing uracil and kanamycin (each $50 \mathrm{mg} \mathrm{l}^{-1}$ ). After $48 \mathrm{~h}$ at $30^{\circ} \mathrm{C}$, the resulting colonies were screened on solid medium for dual uracil auxotrophy and kanamycin resistance. Several uracil-dependent strains were isolated by transposon mutagenesis but only two were characterized further.

The second method of uracil auxotroph isolation involved conventional chemical mutagenesis and counterselection. Ethylmethane sulphonate (EMS) mutagenesis was done as described by Watson \& Holloway (1976). Exponentially growing nutrient broth cultures $(5 \mathrm{ml})$ of $P$. fluorescens cells were treated with $0.05 \mathrm{ml} \mathrm{EMS}$ at $30^{\circ} \mathrm{C}$ for $1 \mathrm{~h}$ without shaking. The cultures were diluted $1: 30$ in nutrient broth and shaken at 200 r.p.m. overnight at $30^{\circ} \mathrm{C}$. The cells were washed with minimal medium several times then resuspended in $10 \mathrm{ml}$ of minimal medium prior to the addition of D-cycloserine $\left(100 \mathrm{mg} \mathrm{l}^{-1}\right)$ (Ornston $e t$ al., 1969). After $2 \mathrm{~h}$ of shaking at $30^{\circ} \mathrm{C}$, the cells were collected, washed and suspended in minimal medium supplemented with $50 \mathrm{mg}$ uracil $\mathrm{l}^{-1}$. After growth at $30^{\circ} \mathrm{C}$ overnight, dilutions of the saturated cultures were spread onto minimal medium agar plates containing uracil (50 $\mathrm{mg}^{-1}$ ). Colonies were picked from these plates after $48 \mathrm{~h}$ at $30^{\circ} \mathrm{C}$ and tested for their growth at $30^{\circ} \mathrm{C}$ on minimal medium plates as well as on minimal medium plates with uracil $\left(50 \mathrm{mg} \mathrm{l}^{-1}\right)$. Three uracil-requiring strains were isolated by this procedure.

Each mutant strain was tested for its ability to grow on carbamoyl aspartate, L-dihydroorotate, orotic acid, uracil, dihydrouracil, cytosine, uridine, cytidine, UMP and cytidine 5 '-monophosphate (CMP). Initially, approximately $10^{7}$ cells of each mutant strain were spread onto minimal medium agar plates. A glass microfibre filter disk $(2 \mathrm{~cm}$ diam.) saturated with a sterile solution of the test compound (1.5-2 mg $\mathrm{ml}^{-1}$ ) was then placed at the centre of each plate. After $8 \mathrm{~d}$ at $30^{\circ} \mathrm{C}$, all plates were examined and recorded as positive if there was confluent growth surrounding the disk.

Growth conditions. All liquid cultures were provided with aeration by shaking ( 200 r.p.m.) and were incubated at $30^{\circ} \mathrm{C}$. The doubling times of the mutant strains in various media were derived spectrophotometrically. The optical density at $600 \mathrm{~nm}$ of each culture was examined at selected time intervals.

Preparation of cell extracts. To investigate de novo pyrimidine biosynthetic pathway enzyme activities in $P$. fluorescens, cell-free extracts were prepared from $20 \mathrm{ml}$ cultures. Cells were collected by centrifugation during the late exponential phase of growth, washed and resuspended in $2 \mathrm{ml} 20 \mathrm{~mm}$-Tris/HCl buffer, $\mathrm{pH} 8 \cdot 0$, containing $1 \mathrm{~mm}$ 2-mercaptoethanol (Condon et al., 1976). The suspension was subjected to ultrasonic disruption for a total of $3 \mathrm{~min}$ at $0{ }^{\circ} \mathrm{C}$. The disrupted cells were centrifuged at $1935 \mathrm{~g}$ for $15 \mathrm{~min}$ at $4{ }^{\circ} \mathrm{C}$. The resulting extract was dialysed for $18 \mathrm{~h}$ against 50 vols resuspension buffer at $4^{\circ} \mathrm{C}$ and was then assayed.

For the pyrimidine starvation experiments, uracil-requiring mutants or uracil-requiring and kanamycin-resistant mutants were grown, respectively, in minimal medium containing $50 \mathrm{mg}$ uracil $1^{-1}$ or $50 \mathrm{mg}$ uracil and kanamycin $1^{-1}$, to the late exponential phase of growth. The cells were collected, washed and resuspended in minimal medium lacking only uracil while maintaining sterile conditions. After $1 \mathrm{~h}$ of pyrimidine starvation, the cells were collected and extracts prepared as described above.

When determining if the rise in dihydroorotase activity observed after orotic acid supplementation was dependent upon protein synthesis, strain A126 was grown in glucose minimal medium cultures $(50 \mathrm{ml})$ until mid-exponential phase was reached. At this point, the cultures were divided evenly into two separate cultures. To one culture chloramphenicol $\left(100 \mathrm{mg} \mathrm{l}^{-1}\right)$ and orotic acid $\left(50 \mathrm{mg} \mathrm{l}^{-1}\right)$ were added, while to the other orotic acid $\left(50 \mathrm{mg} \mathrm{l}^{-1}\right)$ only was added. After $2 \mathrm{~h}$ at $30^{\circ} \mathrm{C}$, each culture was collected, processed and assayed for dihydroorotase activity only.

Enzyme assays. Five de novo pyrimidine biosynthetic pathway enzymes were assayed. Aspartate transcarbamoylase (EC 2.1.3.2) was assayed using a reaction mix $(1 \mathrm{ml})$ that contained $100 \mathrm{mM}-\mathrm{Tris} / \mathrm{HCl}$ buffer, pH 8.5, 10 mM-L-aspartate pH 8.5, 1 mM-dilithium carbamoyl phosphate and cell-free extract. The reaction mixture was incubated at $30^{\circ} \mathrm{C}$ and assayed over a $30 \mathrm{~min}$ period (Adair \& Jones, 1972). At various time intervals, $1 \mathrm{ml}$ of the colour mix of Prescott \& Jones (1969) was added directly to the assay tubes to stop the reaction. After colour mix addition, the tubes were capped with marbles and placed in the dark at room temperature for at least $15 \mathrm{~h}$ and then were incubated at $45^{\circ} \mathrm{C}$ for $70-75 \mathrm{~min}$ under fluorescent lighting. The absorbance of each assay tube was determined at $466 \mathrm{~nm}$ and activity was derived using an experimentally calculated absorption coefficient.

Dihydroorotase (EC 3.5.2.3) was assayed using a mixture $(1 \mathrm{ml})$ that contained $100 \mathrm{mM}$-Tris/HCl buffer, $\mathrm{pH} 8.5,1 \mathrm{mM}$-EDTA, 2 mM-Ldihydroorotate and cell-free extract (Beckwith et al., 1962). The reaction mixture was incubated at $30^{\circ} \mathrm{C}$. At various time intervals over a $30 \mathrm{~min}$ assay period, $1 \mathrm{ml}$ of colour mix was added to the assay tubes which were then processed as described for the aspartate transcarbamoylase assay (Prescott \& Jones, 1969).

A modified assay mixture $(1 \mathrm{ml})$ for dihydroorotate dehydrogenase (EC 1.3.3.1), containing $100 \mathrm{mM}$-Tris/ $\mathrm{HCl}$ buffer, $\mathrm{pH} 8.5,2 \mathrm{mM}-\mathrm{L}$ dihydroorotate and cell-free extract, was used (Kelln et al., 1975). The reaction was followed at $25^{\circ} \mathrm{C}$ by observing the increase in absorbance at $290 \mathrm{~nm}$ and using a molar absorption coefficient of $6.50 \times 10^{3} 1$ $\mathrm{mol}^{-1} \mathrm{~cm}^{-1}$.

The activity of orotate phosphoribosyltransferase (EC 2.4.2.10) was measured at $25^{\circ} \mathrm{C}$ according to the assay procedure of Schwartz \& Neuhard (1975).

The final de novo pyrimidine pathway enzyme assayed was OMP decarboxylase (EC 4.1 .1 .23$)$. The assay mixture ( $1 \mathrm{ml}$ ) contained 100 $\mathrm{mM}$-Tris/HCl buffer, $\mathrm{pH} 8.5,20 \mathrm{mM}-\mathrm{MgCl}_{2}, 0.5 \mathrm{~mm}$-OMP and cell-free extract. Assay mixtures were incubated at $30^{\circ} \mathrm{C}$ and the reaction was halted by the addition of $1 \mathrm{M}-\mathrm{HClO}_{4}(0.5 \mathrm{ml})$. After centrifugation of the precipitated protein, the decrease in absorbance of the supernatant fluid at $285 \mathrm{~nm}$ was measured and activity calculated using a molar absorption coefficient of $2.46 \times 10^{3} 1 \mathrm{~mol}^{-1} \mathrm{~cm}^{-1}$.

Protein was determined by the method of Bradford (1976) where lysozyme served as the standard protein. Specific activity was expressed as nmol substrate utilized or product formed $\mathrm{min}^{-1}$ ( $\mathrm{mg}$ protein $)^{-1}$. All values represented the mean of two separate determinations that were within $10 \%$ error.

Chemicals. The source of kanamycin, novobiocin, EMS, D-cycloserine, L-aspartic acid, dilithium carbamoyl phosphate, antipyrine, diacetylmonoxime, carbamoyl aspartate, dihydroorotate, orotic acid, lysozyme, 5-phosphoribosyl-1-pyrophosphate, OMP, chloramphenicol, pyrimidine bases and nucleosides was Sigma. UMP and CMP were obtained from Calbiochem. GN-6 Metricel membrane filters were purchased from Gelman Sciences. Glass microfibre GF-C filters were obtained from Whatman.

\section{Results}

Initially, the de novo pyrimidine biosynthetic enzyme levels of the $P$. fluorescens wild-type strain grown in minimal medium alone or minimal medium containing an exogenous pyrimidine base were determined (Table 1). The first enzyme investigated was aspartate transcarbamoylase. Addition of uracil to the medium depressed 
Table 1. Effects of pyrimidines upon five de novo pyrimidine biosynthetic enzyme activities in the wild-type strain A126

Growth conditions and enzyme assays were as described in Methods. Uracil or orotic acid were added to the medium at a final concentration of $50 \mathrm{mg} \mathrm{l}^{-1}$. Specific activity is stated as nmol $\mathrm{min}^{-1}$ (mg protein $)^{-1}$. Each value is the mean of two separate determinations within $10 \%$ error.

\begin{tabular}{lccc}
\hline \hline & \multicolumn{2}{c}{ Specific activity after growth on: } \\
\cline { 2 - 4 } \multicolumn{1}{c}{ Enzyme } & $\begin{array}{c}\text { No } \\
\text { supplement }\end{array}$ & Uracil & Orotic acid \\
\hline Aspartate transcarbamoylase & 14 & 8 & 13 \\
Dihydroorotase & 13 & 8 & 29 \\
Dihydroorotate dehydrogenase & 9 & 7 & 4 \\
Orotate phosphoribosyltransferase & 51 & 31 & 33 \\
OMP decarboxylase & 44 & 25 & 28 \\
\hline \hline
\end{tabular}

aspartate transcarbamoylase activity when compared to the activity in cells grown in minimal medium. When orotic acid was added, no significant change in activity could be observed. Dihydroorotase activity dropped when uracil was added to the medium. On the other hand, adding orotic acid doubled dihydroorotase activity. If chloramphenicol was included in the medium in addition to orotic acid, enzyme activity was $13 \mathrm{nmol}$ $\min ^{-1}$ (mg protein) $)^{-1}$ (mean of two separate determinations within $10 \%$ error) after $2 \mathrm{~h}$ of growth. In contrast, cells grown for $2 \mathrm{~h}$ on medium containing solely orotic acid had a dihydroorotase activity of $29 \mathrm{nmol} \mathrm{min}^{-1}(\mathrm{mg}$ protein $)^{-1}$ (mean of two separate determinations within $10 \%$ error). The increase in enzyme activity is dependent upon the synthesis of additional protein. From these results, it would seem that dihydroorotase is induced by orotic acid or a metabolite of orotic acid. Addition of either uracil or orotic acid decreased the level of dihydroorotate dehydrogenase in the wild-type strain; the largest decrease in activity occurred if the strain was grown in the presence of orotic acid (Table 1). The final two enzymes of the de novo pathway, orotate phosphoribosyltransferase and OMP decarboxylase, had their activity lowered by addition of either uracil or orotic acid to the minimal medium with uracil diminishing activity the greatest (Table 1).

To determine if the level of pyrimidine ribonucleotides could influence the regulation of this pathway, it was necessary to do pyrimidine starvation experiments. This necessitated the isolation of uracil-requiring mutant strains of $P$. fluorescens. The uracil-requiring mutants in this study were isolated by transposon mutagenesis and by conventional EMS mutagenesis in conjunction with cycloserine counterselection (see Methods). The pattern of growth on various de novo pathway products as well as on pyrimidine bases, ribonucleosides and ribonucleotides was studied. None of the mutants could utilize cytidine, dihydrouracil, CMP, dihydroorotate or carbamoyl aspartate as a sole pyrimidine source. Strains CW1004 and CW1010 grew on UMP, uracil, cytosine and uridine. Growth on cytosine and uridine is probably related to the presence of cytosine deaminase and nucleoside hydrolase, respectively, in $P$. fluorescens (Terada et al., 1967; Sakai et al., 1976). It was not clear why these strains grew on UMP, even though their growth was very slow (Table 2), but dephosphorylation of nucleotides has been inferred for other bacteria (Schwan \& Holldorf, 1975; Kelln et al., 1985; West, 1989). Strains CW1011 and CW 1012 were able to grow on orotic acid, uracil, cytosine and uridine. Strain CW1013 grew on uracil, cytosine and uridine. It was the least versatile strain, with respect to growth on the tested

Table 2. Growth rates of mutant strains in pyrimidine-containing minimal media

Each strain was grown in minimal medium containing $50 \mathrm{mg}$ pyrimidine $1^{-1}$ at $30^{\circ} \mathrm{C}$. Doubling times are in $\min$.

\begin{tabular}{|c|c|c|c|c|c|}
\hline \multirow[b]{2}{*}{ Strain (genotype) } & \multicolumn{5}{|c|}{ Doubling time of strains growing on: } \\
\hline & Uracil & Uridine & UMP & Cytosine & Orotic acid \\
\hline $\begin{array}{l}\text { CW1004 } \\
\text { (Tn5::pyrE1) }\end{array}$ & 75 & 134 & 1491 & 590 & - \\
\hline $\begin{array}{l}\text { CW } 1010 \\
\text { (Tn5::pyrE2) } \\
\text { CW } 1011\end{array}$ & 74 & 450 & 884 & 600 & - \\
\hline $\begin{array}{r}(\text { pyrBl) } \\
\text { CW1012 }\end{array}$ & 53 & 170 & - & 540 & 100 \\
\hline $\begin{array}{r}(\text { pyrB2) } \\
\text { CW1013 }\end{array}$ & 63 & 477 & - & 313 & 69 \\
\hline
\end{tabular}


Table 3. De novo pyrimidine biosynthetic enzyme activities in mutant strains and in selected mutant strains starved of uracil

Strains CW1004 or CW1011 were grown at $30^{\circ} \mathrm{C}$ in glucose minimal medium containing $50 \mathrm{mg}$ kanamycin and uracil $\mathrm{l}^{-1}$ or $50 \mathrm{mg}$ uracil $\mathrm{l}^{-1}$, respectively. Strains $\mathrm{CW} 1010, \mathrm{CW} 1012$ and $\mathrm{CW} 1013$ were grown at $30^{\circ} \mathrm{C}$ in glucose minimal medium supplemented with $50 \mathrm{mg}$ uracil $1^{-1}$ (+uracil) or were starved of uracil (-uracil) for $1 \mathrm{~h}$ at $30^{\circ} \mathrm{C}$. The medium for strain $\mathrm{CW} 1010$ also contained 50 mg kanamycin $1^{-1}$. Extracts were prepared and enzymes assayed as given in Methods. Specific activity is expressed as nmol $\mathrm{min}^{-1}$ (mg protein) ${ }^{-1}$. Each value is the mean of two separate determinations within $10 \%$ error. ND, not determined.

Specific activity of strain (genotype):

\begin{tabular}{|c|c|c|c|c|c|c|c|c|}
\hline \multirow[b]{2}{*}{ Enzyme } & \multirow{2}{*}{$\begin{array}{c}\mathrm{CW} 1004 \\
(\operatorname{Tn} 5: \text { :pyrEI) }\end{array}$} & \multicolumn{2}{|c|}{$\begin{array}{c}\text { CW1010 } \\
(\operatorname{Tn} 5: p y r E 2)\end{array}$} & \multirow{2}{*}{$\begin{array}{c}\text { CW1011 } \\
(\text { pyrBI) }\end{array}$} & \multicolumn{2}{|c|}{$\begin{array}{c}\text { CW1012 } \\
\text { (pyrB2) }\end{array}$} & \multicolumn{2}{|c|}{$\underset{(\text { pyrC) }}{\mathrm{CW} 1013}$} \\
\hline & & +Uracil & -Uracil & & + Uracil & -Uracil & + Uracil & -Uracil \\
\hline $\begin{array}{l}\text { Aspartate } \\
\text { transcarbamoylase }\end{array}$ & 13 & 12 & 15 & $<1$ & $<1$ & ND & 8 & 25 \\
\hline Dihydroorotase & 12 & 11 & 9 & 10 & 16 & 31 & 1 & ND \\
\hline $\begin{array}{l}\text { Dihydroorotate } \\
\text { dehydrogenase }\end{array}$ & 7 & 4 & 4 & 5 & 6 & 3 & 6 & 18 \\
\hline $\begin{array}{l}\text { Orotate phospho- } \\
\text { ribosyltransferase } \\
\text { OMP decarboxylase }\end{array}$ & $\begin{array}{l}<1 \\
25\end{array}$ & $\begin{array}{l}<1 \\
21\end{array}$ & $\begin{array}{r}\mathrm{ND} \\
2\end{array}$ & $\begin{array}{l}33 \\
29\end{array}$ & $\begin{array}{l}28 \\
41\end{array}$ & $\begin{array}{l}31 \\
21\end{array}$ & $\begin{array}{l}32 \\
22\end{array}$ & $\begin{array}{l}28 \\
44\end{array}$ \\
\hline
\end{tabular}

compounds, of the strains isolated. In addition, the doubling time of each strain was determined in the presence of uracil, uridine or cytosine (Table 2). Clearly, all strains grew well on uracil. Growth rates upon uridine and cytosine as pyrimidine sources appeared to vary with the strain being studied. Only strains CW1004 and CW1010 or strains CW1011 and CW1012, respectively, were investigated as to their doubling time in the presence of UMP or orotic acid, respectively, as a pyrimidine source (Table 2). The former strains grew poorly on UMP while the latter strains grew rapidly on orotic acid (Table 2).

The de novo pyrimidine pathway enzymes were assayed in each mutant strain to confirm its enzymic defect (Table 3). Strains CW1011 and CW1012 contained diminished aspartate transcarbamoylase activity while strains CW1004 and CW1010 were deficient for orotate phosphoribosyltransferase activity. Low dihydroorotase activity could be detected in strain CW1013. Aspartate transcarbamoylase and dihydroorotase activities in the mutant strains were elevated respective to their activities in the uracil-grown cells of the wild-type strain. Dihydroororate dehydrogenase, orotate phosphoribosyltransferase and OMP decarboxylase activities in the mutant strains, in general, were comparable to those detected in the uracil-grown cells of the wild-type strain.

Strains CW1010, CW1012 and CW1013 were each subjected to pyrimidine starvation for a period of $1 \mathrm{~h}$. Pyrimidine starvation experiments could provide an indication of gene expression regulation if derepression of enzyme activity is observed (Williams \& O'Donovan, 1973). After strain CW 1010 was starved, a slight increase in aspartate transcarbamoylase activity was seen (Table 3). Interestingly, after starvation of strain CW1013, an approximately three-fold increase in transcarbamoylase activity was observed relative to the activity of nonstarved cells (Table 3). Dihydroorotase specific activity for strains CW1010 and CW1012 was investigated after the starvation period. Relative to the activity of nonstarved cells, it was found that the activity of the former strain was depressed by pyrimidine limitation while approximately a twofold increase in enzyme activity was noted for the latter strain (Table 3). Starvation of strain CW1010 had little effect upon dihydroorotate dehydrogenase activity (Table 3 ). Following pyrimidine limitation, dehydrogenase activity was reduced by $50 \%$ in strain CW1012 but was elevated about threefold in strain CW 1013 compared to the activity of cells grown in saturating uracil (Table 3). The activity of orotate phosphoribosyltransferase in strains CW1012 and CW 1013 was largely unchanged by pyrimidine starvation (Table 3). Pyrimidine-starved cells exhibited diminished OMP decarboxylase activity in strains CW1010 and CW1012 but contained elevated decarboxylase activity in strain CW1013 (Table 3).

\section{Discussion}

Previous studies have examined de novo pyrimidine biosynthesis in aerobic pseudomonads (Isaac \& Holloway, 1968; Condon et al., 1976). The pyrimidine biosynthetic pathways in $P$. aeruginosa and in $P$. putida were found to involve the same enzyme activities as found in other bacterial de novo pyrimidine biosynthetic 
pathways (Isaac \& Holloway, 1968; O'Donovan \& Neuhard, 1970; Condon et al., 1976). This was also found to be true in this investigation for $P$. fluorescens.

In $P$. aeruginosa, mutants lacking aspartate transcarbamoylase, dihydroorotate dehydrogenase, orotate phosphoribosyltransferase or OMP decarboxylase activity were isolated (Isaac \& Holloway, 1968; Holloway et al., 1979). Although capable of using uracil as a pyrimidine source, none of these mutants were capable of growing on intermediates of the de novo pathway. The activity of aspartate transcarbamoylase, dihydroorotase, dihydroorotate dehydrogenase or orotate phosphoribosyltransferase remained unaffected by adding uracil to the media (Isaac \& Holloway, 1968). It was shown that derepression of enzyme synthesis failed to occur under conditions of limiting uracil but a partial induction of dihydroorotate dehydrogenase and orotate phosphoribosyltransferase was seen when 6-azauracil was used to inhibit pyrimidine biosynthesis in $P$. aeruginosa (Isaac \& Holloway, 1968). At the level of enzyme activity, there was inhibition of aspartate transcarbamoylase by ATP, CTP or UTP (Isaac \& Holloway, 1968).

In $P$. putida, the isolation of a carbamoyl phosphate synthetase, an aspartate transcarbamoylase and an OMP decarboxylase mutant has been reported (Condon et al., 1976). Cytosine or uracil served as a pyrimidine source for these mutants. Repression of aspartate transcarbamoylase, dihydroorotase, dihydroorotate dehydrogenase, orotate phosphoribosyltransferase or OMP decarboxylase synthesis was not observed but about a twofold increase in the above enzyme activities was noted following pyrimidine starvation of the uracil-auxotrophic mutants (Condon et al., 1976). It was concluded that de novo pyrimidine pathway enzyme synthesis in $P$. putida was regulated. In addition, aspartate transcarbamoylase was shown to be inhibited by pyrophosphate, CTP, UTP and ATP (Condon et al., 1976).

In this study, the de novo pyrimidine biosynthetic pathway of $P$. fluorescens has been explored. Several pyrimidine auxotrophic mutants were isolated and subsequently characterized. Unlike $P$. aeruginosa, some of the mutants isolated from $P$. fluorescens were capable of growing upon intermediates of the de novo pathway. As was observed for $P$. putida, the mutant strains in this study were able to utilize cytosine as a pyrimidine source. There were noticeable differences in the growth rates between the $p y r B$ strains (and to a lesser extent between the $p y r E$ strains). on the pyrimidine sources examined. It is not entirely clear why these differences exist but several explanations are possible. One of the $p y r B$ strains could contain a secondary spontaneous or EMS-induced mutation that affects pyrimidine transport. If this mutation affected the affinity of a permease responsible for transporting uridine, cytosine and orotic acid, the differences in growth rates could be explained. A less plausible explanation might be the induction of a regulatory mutation affecting pyrimidine base and ribonucleoside metabolism. The above explanations would also seem to be relevant to the observed variations in the growth rates of the pyrE strains upon uridine and UMP. Although a secondary mutation affecting transport would seem to be the most likely answer, it is also possible that a mutation altering nucleoside hydrolase activity may have occurred in one of these strains.

With respect to regulation of the de novo pathway, orotic acid addition to minimal medium cultures of strain A126 induced dihydroorotase synthesis. Following pyrimidine limitation, the level of this enzyme increased about twofold for strain CW1012 but decreased for strain CW1010. Since strain CW1010 should accumulate orotic acid after pyrimidine starvation, orotic acid must not serve as the inducer of dihydroorotase synthesis. Perhaps a metabolite of orotic acid served as the inducer. It is also possible that a second dihydroorotase activity may be inducible in strain A126. This has been noted for an inducible dihydroorotate dehydrogenase present in a soil pseudomonad (Taylor et al., 1966). This pseudomonad was shown to contain two dihydroorotate dehydrogenases. The biosynthetic enzyme was synthesized constitutively while the degradative dehydrogenase was induced by orotate (Taylor et al., 1966). Unlike $P$. aeruginosa and $P$. putida, the presence of uracil in the growth medium did depress the levels of the de novo pyrimidine pathway enzymes investigated. Moreover, after pyrimidine limitation of strain CW1013, aspartate transcarbamoylase and dihydroorotate dehydrogenase activities increased about threefold while OMP decarboxylase activity increased twofold. It could be that this effect is strainspecific or it might be that partial pyrimidine starvation allowed the accumulation of an inducer compound that stimulated their transcription. It is interesting to note that OMP decarboxylase activity in the wild-type strain appeared to be repressible by pyrimidines while decarboxylase activity in strains CW1010 and CW1012 was not derepressed by pyrimidine starvation. Perhaps this enzyme is subject to protease degradation during complete pyrimidine limitation. Only partial pyrimidine limitation can be achieved for the bradytrophic mutant strain CW1013 and this may be the reason for its enhanced decarboxylase activity observed after the starvation period.

In conclusion, this study indicates that regulation of $d e$ novo pyrimidine biosynthesis in $P$. fluorescens does exist at the level of enzyme synthesis. Further work on pyrimidine biosynthesis in the aerobic pseudomonads is necessary if regulation of the de novo pathway is to be fully comprehended.

We wish to thank M. S. Shanley and L. N. Ornston for providing the pseudomonad strain used in this study. 


\section{References}

ADAIR, L. B. \& JoNES, M. E. (1972). Purification and characteristics of aspartate transcarbamoylase from Pseudomonas fluorescens. Journal of Biological Chemistry 247, 2308-2315.

Beckwith, J. R., Pardee, A. B., Austrian, R. \& Jacob, F. (1962). Coordination of the synthesis of the enzymes in the pyrimidine pathway of E. coli. Journal of Molecular Biology 5, 618-634.

Beringer, J. E., Beynon, J. L., Buchanan-Wollaston, A. V. \& Johnston, A. W. B. (1978). Transfer of the drug-resistance transposon Tn 5 to Rhizobium. Nature, London 276, 633-634.

BRADFORD, M. M. (1976). A rapid and sensitive method for the quantitation of microgram quantities of protein utilizing the principle of dye-binding. Analytical Biochemistry 72, 248-254.

Condon, S., Collins, J. K. \& O'Donovan, G. A. (1976). Regulation of arginine and pyrimidine biosynthesis in Pseudomonas putida. Journal of General Microbiology 92, 375-383.

Gantotti, B. V., KindLE, K. L. \& BEER, S. V. (1981). Transfer of the drug-resistance transposon Tn5 to Erwinia herbicola and the induction of insertion mutations. Current Microbiology 6, 377-381.

Holloway, B. W., Krishnapillai, V. \& Morgan, A. F. (1979). Chromosomal genetics of Pseudomonas. Microbiological Reviews 43, 73-102.

IsaAC, J. H. \& Holloway, B. W. (1968). Control of pyrimidine biosynthesis in Pseudomonas aeruginosa. Journal of Bacteriology 96, 1732-1741.

Kelln, R. A., Kinahan, J. J., Foltermann, K. F. \& O'Donovan, G. A. (1975). Pyrimidine biosynthetic enzymes of Salmonella typhimurium, repressed specifically by growth in the presence of cytidine. Journal of Bacteriology 124, 764-774.

Kelln, R. A., Neuhard, J. \& Stauning, L. (1985). Isolation and characterization of pyrimidine mutants of Salmonella typhimurium altered in expression of pyrC, pyrD, and pyrE. Canadian Journal of Microbiology 31, 981-987.

Monticello, D. J., Bakker, D., Schell, M. \& Finnerty, W. R. (1985). Plasmid-borne Tn5 insertion mutation resulting in accumulation of gentisate from salicylate. Applied and Environmental Microbiology 49, 761-764.
NeumanN, J. \& Jones, M. E. (1964). End-product inhibition of aspartate transcarbamylase in various species. Archives of Biochemistry and Biophysics 104, 438-447.

O'Donovan, G. A. \& NeuHard, J. (1970). Pyrimidine metabolism in microorganisms. Bacteriological Reviews 34, 278-343.

Ornston, L. N., Ornston, M. K. \& ChOU, G. (1969). Isolation of spontaneous mutant strains of Pseudomonas putida. Biochemical and Biophysical Research Communications 36, 179-184.

PrescotT, L. M. \& Jones, M. E. (1969). Modified methods for the determination of carbamyl aspartate. Analytical Biochemistry 32 , 408-419.

SAKAI, T., YU, T. \& OMata, S. (1976). Distribution of enzymes related to cytidine degradation in bacteria. Agricultural and Biological Chemistry 40, 1893-1895.

SCHWAN, H. \& HolldoRF, A. W. (1975). Effective utilization of exogenous deoxythymidine-5'-monophosphate for DNA synthesis in enterobacteria. FEBS Letters 57, 179-182.

SCHWARTZ, M. \& NeUHARD, J. (1975). Control of expression of the pyr genes in Salmonella typhimurium: effects of variations in uridine and cytidine nucleotide pools. Journal of Bacteriology 121, 814-822.

STANIER, R. Y. (1947). Simultaneous adaption : a new technique for the study of metabolic pathways. Journal of Bacteriology 54, 339-348.

Stanier, R. Y., Palleroni, N. J. \& Doudoroff, M. (1966). The aerobic pseudomonads: a taxonomic study. Journal of General Microbiology 43, 159-271.

TAYloR, W. H., TAYloR, M. L. \& Eames, D. F. (1966). Two functionally different dihydroorotic dehydrogenases in bacteria. Journal of Bacteriology 91, 2251-2256.

Terada, M., Tatibana, M. \& Hayaishi, O. (1967). Purification and properties of nucleoside hydrolase from Pseudomonas fluorescens. Journal of Biological Chemistry 242, 5578-5585.

Watson, J. M. \& Holloway, B. W. (1976). Suppressor mutations in Pseudomonas aeruginosa. Journal of Bacteriology 125, 780-786.

WEST, T. P. (1989). Isolation and characterization of thymidylate synthetase mutants of Xanthomonas maltophilia. Archives of Microbiology 151, 220-222.

Williams, J. C. \& O'Donovan, G. A. (1973). Repression of enzyme synthesis of the pyrimidine pathway in Salmonella typhimurium. Journal of Bacteriology 115, 1071-1076. 